\title{
EFFECT OF PROCESS FACTORS ON SURFACE ROUGHNESS IN DIP CRYOGENIC MACHINING OF AISI 1040 STEEL USING TAGUCHI'S APPROACH
}

\author{
Akshaya T. Poojary ${ }^{1}$, Dharmik U. Sheth ${ }^{2}$, Tirth H. Shah ${ }^{3}$, Akash M. Patil ${ }^{4}$, Rajesh Nayak \\ ${ }^{1}$ Graduate, Mechanical and Manufacturing Dept., Manipal Institute of Technology, Manipal University, Manipal, \\ Karnataka, India, (akshay_poojary@yahoo.co.in). \\ ${ }^{2}$ Graduate, Mechanical Engineering, Vidyavardhini College of Engineering and Technology, Mumbai, Maharashtra, \\ India, (dharmiksheth49@yahoo.in). \\ ${ }^{3}$ Student, Mechanical Engineering Dept., Dwarkadas J. Sanghvi College of Engineering, Mumbai University, \\ Mumbai, Maharashtra, India, (tirthshah@live.in). \\ ${ }^{4}$ Graduate, Mechanical Engineering, Shree Gulabrao Deokar College of Engineering, North Maharashtra University, \\ Jalgaon, Maharashtra, India, (patilakash44@gamil.com). \\ ${ }^{5}$ Asst. Professor (Selection Grade), Mechanical and Manufacturing Dept., Manipal Institute of Technology, Manipal \\ University, Manipal, Karnataka, India (rajesnayak@gmail.com).
}

\begin{abstract}
Surface roughness is the most prominent factor in machining of any metal. The efficacy of a machining process is largely dependant on quality of surface roughness obtained for the workpiece. This experiment involves turning of AISI 1040 steel under dry, conventional cutting fluid (wet) and cryogenic condition using high speed steel cutting tool. The surface roughness values for each of the trials were measured and recorded.Taguchi's signal-to-noise $(\mathrm{S} / \mathrm{N})$ ratio was introduced to this experiment inorder to determine the significant control factor (cutting speed, feed rate or depth of cut) for all three machining processes along with the optimal control factor combination. The control factors were set in an orthogonal array (L27). MINITAB 16 was used to determine the $\mathrm{S} / \mathrm{N}$ ratio valuesfor all the different interactions by incorporating "smaller the better" characteristic. The analysis concluded that the significant control factor for dry machining was feed rate, depth of cut for conventional cutting fluid (wet) machining and feed rate for cryogenic machining. Feed rate of $0.10 \mathrm{~mm} / \mathrm{rev}$,depth of cut of $0.25 \mathrm{~mm}$ and cutting speed of $43.73 \mathrm{~m} /$ minare the optimumcontrol factor combination to be set to procure minimum surface roughness in each of the machining process. Even though the optimum combinations were observed to be same for all the machining process, there was an improvement of $53.57 \%$ in cryogenic machining observed in analogous to dry machining and an improvement of $33.92 \%$ in cryogenic machining was observed in correspondent to wet machiningfor $\mathrm{S} / \mathrm{N}$ ratio values of optimum control factor combinations. It was also observed that the $\mathrm{S} / \mathrm{N}$ ratio values for optimum combination (minimum surface roughness) in cryogenic machining were the least in analogous to other forms of machining. Thus this developed model concludes that the dip cryogenic machining should be adapted in order to procure minimum surface roughness.
\end{abstract}

Keywords -AISI 1040 steel, dry machining, wet machining, cryogenic machining, surface roughness and Taguchi's approach.

\section{INTRODUCTION}

An AISI 1040 steel round bar was dipped in liquid nitrogen (LN2) and turned on lathe machine as an experiment to observe and scrutinize the effect on cutting force, surface roughness and chip morphology. The experiment was conducted under dry, conventional cutting fluid (wet) and LN2 conditions. The results were in favour of LN2 machining but the optimum values of each factor had to be determined inorder to procure the minimum surface roughness value. Thus Taguchi's methodologywas implemented to determineprimarily the optimum value of control factors and secondly the parameters which play a significant role in direct variation of surface roughness.
In turning of a steel bar, the end result depends upon numerous factors. The feed rate, cutting speed and depth of cut are the decisive factors on which the desired cutting force, surface roughness and chip thickness values are reliant on. It is convenient to keep a track of one factor with respect to one parameter and to conclude whether they are directly or indirectly proportional to each other. It becomes difficult to analyze and conclude these multiple factors relative to the various parameters, it worsens when there are multiple levels incorporated in the same experiment for different factors. The results obtained for such experiments are generally aberrant. It is necessary to consider and analyze all factors and parameters relatively so as to know the factors that play a significant role in obtaining the desired value of the parameter. Thus to ameliorate the 
desired value of the parameter Taguchi's $(\mathrm{S} / \mathrm{N})$ ratio method is used to optimize the control factors.

Taguchi's signal-to-noise ratio is a parameter design which forms a strategic tool for robust design. The method provides the optimum design for cost, quality and performance which are highly needed in any industry. Robust design utilizes two most crucial strategic methods namely the S/Nratio and the orthogonal array. In $(\mathrm{S} / \mathrm{N})$ ratio method more focus is given to the variations in the experiment for measuring the quality whereas orthogonal array has the potential to allow multiple factors simultaneously. In S/N ratio method, Dr. Genichi Taguchi has assigned signals as the beneficial factors required to obtain the desired result of the parameter and noise as those factors which abates or deteriorates the desired result.

\section{LITERATURE REVIEW}

[2] Aman Agarwal et al. performed CNC turning operation on AISI P-20 tool steel and analyzed the power consumption using Taguchi's technique. The results pointed out that the cryogenic machining is the utmost vital factor in abating the power consumption, cutting speed and depth of cut. It was recorded that the effects of feed rate and nose radius proved to be inconsequential in comparison to other process factors.

[3] Anil Gupta et al. turned AISI P-20 steel tool in CNC machine with the help of TiN layered tungsten carbide cutting tool and optimized using Taguchi-fuzzy hybrid approach. It was noticed that the cutting speed at $160 \mathrm{~m} / \mathrm{min}$, feed rate at $0.1 \mathrm{~mm} / \mathrm{rev}$, nose radius at $0.8 \mathrm{~mm}$ and depth of cut at $0.2 \mathrm{~mm}$ under cryogenic condition were the utmost beneficial cutting factors for high speed CNC turning of the material.

[4] Ilhan Asilturk and Harun Akkusperformed turning operation on AISI 4140 (51 HRC) in a CNC turning machine using coated carbide cutting tools. Taguchi's statistical method of signal to noise ratio was applied to examine the effects on surface roughness ( $\mathrm{Ra}$ and $\mathrm{Rz}$ ) caused by cutting speed, feed rate, and depth of cut. The outcomes proved feed rate to be highly influential over surface roughness ( $\mathrm{Ra}$ and $\mathrm{Rz}$ ).

[5] Ilhan Asilturk and Suleyman Neseli turned AISI 304 austenitic stainless workpiece on CNC turning machine using layered carbide insert cutting tool under ambient conditions.Cutting speed, feed rate and depth of cut were the cutting parameters which were designed using Taguchi's method. The results highlighted that the feed rate was the governing factor disturbingthe surface roughness and its value was obtained to be minimum when the feed rate and depth of cut were set to the lowermost level and when the cutting speed was set to its uppermost level.

[6] Turgay Kivark et al.performed a drilling experiment on AISI 316 stainless steel blocks in a CNC vertical machining centre under dry conditions with the help of coated and uncoated M35 HSS twist drills. Taguchi's method was adapted to optimize the experiment. It was inferred from the experiment that cutting tools proved to be a significant factor on surface roughness while feed rate proved to be on thrust force.

[7] Mustafa Gunay et al. carried out a turning experiment on high alloy white cast iron (Ni-Hard) with two different workpieces having Rockwell Hardness Number of HRC 50 and HRC 62in a CNC lathe using two different cutting tools namely ceramic and cubic boron nitride $(\mathrm{CBN})$. Taguchi's signal-to-noise $(\mathrm{S} / \mathrm{N})$ ratio was employed to determine the optimal cutting conditions. It was concluded from the experiment that the cutting speed and the feed rate were the paramount control factors having influence on the surface roughness.

[8] Ashok Kumar Sahoo and Swastik Pradhanturned $\mathrm{Al} / \mathrm{SiCp}$ metal matrix composite (MMC) under ambient conditions using uncoated tungsten carbide insert. ANOVA and Taguchi's $(\mathrm{S} / \mathrm{N})$ ratio methods were used to optimize the process parameters namely cutting speed, feed rate and depth of cut for the flank wear (VBc) and surface roughness $(\mathrm{Ra})$. The optimal combinations for flank wear and surface roughness that were witnessed during the analysis were $60 \mathrm{~m} / \mathrm{min}-0.05 \mathrm{~mm} / \mathrm{rev}-0.4 \mathrm{~mm}$ and $180 \mathrm{~m} / \mathrm{min}-0.05 \mathrm{~mm} / \mathrm{rev}$ $0.4 \mathrm{~mm}$ respectively.

[9] K. Venkata Rao et al.conducted boring operation on AISI 1040 steel in order to monitor the cutting tool by analyzing the workpiece vibration and metal volume removed using Taguchi method. Feed rate proved to be a significant parameter for affecting surface roughness and metal volume removed by $55.57 \%$ and $51.26 \%$ respectively.

[10] D. Philip Selvaraj et al. performed the dry turning operation on cast DSS ASTM A 955 grade 5A and grade 4A using $\mathrm{TiC}$ and TiCN coated carbide cutting tool inserts. Taguchi's S/N ratio and ANOVA were implemented to optimize the cutting parameters. Cutting speed of $100 \mathrm{~m} / \mathrm{min}$ and a feed rate of $0.04 \mathrm{~mm} / \mathrm{rev}$ gave an outcome of lowest surface roughness values for both the grades of duplex stainless steel. A cutting speed set at $120 \mathrm{~m} / \mathrm{min}$ with a feed rate of $0.04 \mathrm{~mm} /$ revsecured the lowest cutting force for both the grades of duplex stainless steel.

[11] C.C. Tsao and H. Hocheng conducted a drillingoperation using candle stick drill on composite material which assisted them in predicting and evaluating the thrust force and surface roughness. Taguchi's method was adapted in this experiment. Results discovered that the feed rate and drill diameter were the most crucial factors disturbingthe thrust force. The feed rate and spindle speed contributed the maximum to the surface roughness.

[12] P. Vijian and V.P. Arunachalam used a 3 level orthogonal array inorder to procure the signal to noise ratio. The process parameters affecting the surface roughness of a squeeze casting (is a hybrid metal forming process amalgamatedof casting and forging) performed on LM6 aluminium alloy were optimized.The outcomespointed out that the squeeze cast products procured the ameliorated surface finish due to the squeeze pressure and preheating 
temperature of the die.

[13] L B Abhang and M Hameedullah turned EN-31 steel alloy against tungsten carbide cutting tool insert. Taguchi's method was implemented to optimize the three control factors namely feed rate, depth of cut and lubricant temperature. Minimum surface roughness values were procured for $0.05 \mathrm{~mm} / \mathrm{rev}-0.4 \mathrm{~mm}-10^{\circ} \mathrm{c}$ combination.

[14] V.N. Gaitonde et al.performed a turning operation on brass againstK10 carbide cutting tool. The various factors namely the minimum quantity of lubrication (MQL), cutting speed and feed rate were optimizedby Taguchi's method. The optimized values that encouraged in reduction of surface roughness and specific cutting force are $200 \mathrm{ml} / \mathrm{h}$ for MQL, $200 \mathrm{~m} / \mathrm{min}$ for cutting speed and $0.05 \mathrm{~mm} / \mathrm{rev}$ for feed rate.

\section{EXPERIMENTAL DETAILS}

The turning operation was performed on AISI 1040 steel in PSG A141 lathe (consuming $2.2 \mathrm{KW}$ of power) under dry, conventional cutting fluid (wet) and cryogenic cooling conditions. High speed steel (HSS) which is widely used in industry, was used as a turning tool.The workpiece was immersed incryogenic liquid (LN2) for a specified duration and then clamped on to the chuck for turning operation as shown in fig. 1 .

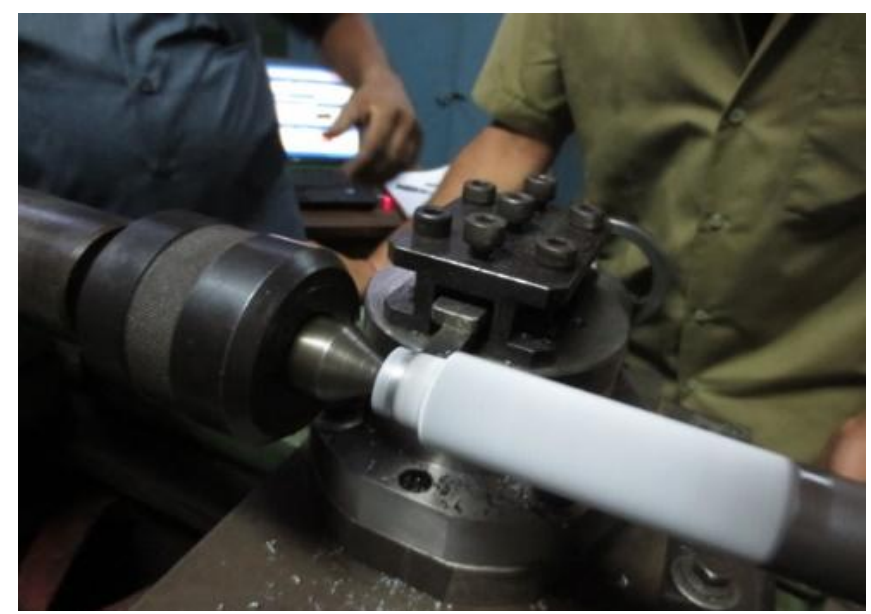

Fig.1: Dip Cryogenic Machining

\subsection{Work Material}

An AISI 1040 steel round bar of $\varnothing 24 \mathrm{~mm}$ and length $304.8 \mathrm{~mm}$ long was used to conduct the experiment. This grade of steel is also called mild steel because of the average carbon content. AISI 1040 steel has established wide application in all scales of industry thus seeking majority of researcher's attention. ${ }^{[15]}$ The percentage chemical composition of AISI 1040 steel is Carbon - 0.37\%-0.44\%, Manganese - $0.60 \%-0.90 \%$, Phosphorus - $0.040 \%$, Sulfur $0.050 \%$. The workpieces used for each of the machining environments (dry, wet and cryogenic) were different but were taken from the same parent material so as to avoid procurement of any aberrant results due to change in chemical composition.

\subsection{Surface Roughness Measuring Instrument.}

The surface roughness of the machined workpieces were measured using Taylor Hobson manufactured instrument Surtronic 3+ (112/1590). The length for which roughness test was carried out was $4 \mathrm{~mm}$. It had a selectable range of $10 \mu \mathrm{m}$, $100 \mu \mathrm{m}$ and $500 \mu \mathrm{m}$. Resolution used to carry out the experiment was $0.5 \mu \mathrm{m}$. The instrument had a selectable cut off value of $0.25 \mathrm{~mm}, 0.8 \mathrm{~mm}$ and $2.50 \mathrm{~mm}$. Skid pick up stylus with diamond tip radius of $5 \mu \mathrm{m}$ was used to quantify the surface roughness. The software used for data acquisition and evaluation of surface roughness was Taly Profile 3.1. Fig.2. shows the photographic view of surface roughness measurement conducted.

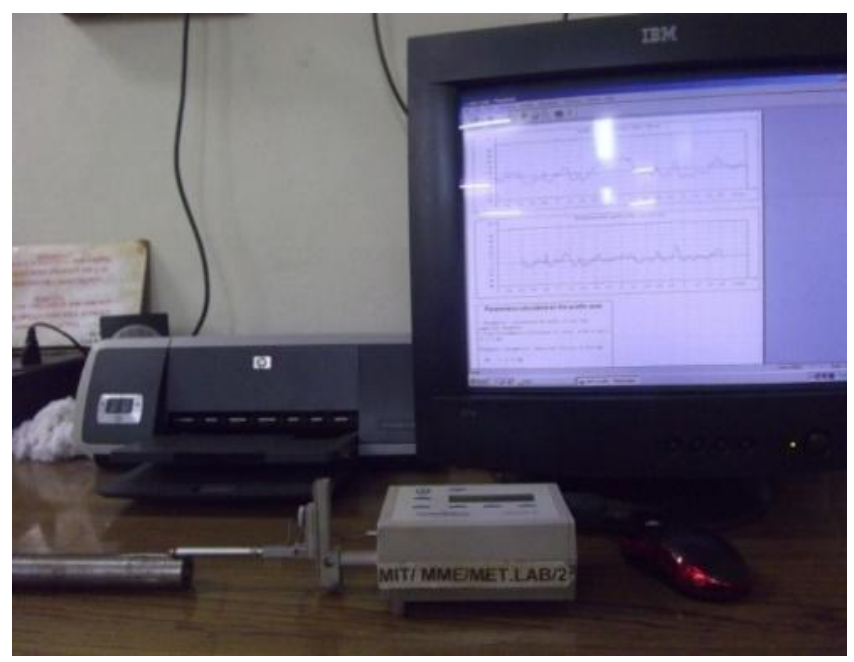

Fig. 2: Photographic View of Surtronic 3+

\subsection{Taguchi's Experimental Design.}

The three control factors in the following experiment are cutting speed, feed rate and depth of cut. The three levels considered for all the three control factors are as shown in table no. 1. Each experiment was conducted thrice and the average value of surface roughness was chosen for the Taguchi's S/N ratio analysis. Orthogonal array of L27 $\left(3^{13}\right)$ was adapted which consisted of 27 rows corresponding to the different combinations of factor. First column was assigned to cutting speed $(\mathrm{m} / \mathrm{min})$, second to feed rate $(\mathrm{mm} / \mathrm{rev})$, third to depth of cut $(\mathrm{mm})$ and the remaining columns to the interactions. The analysis was conducted usingMINITAB 16 which is the most widely used and accurate software for application of design of experiment.

Table No. 1: Process Parameters and levels used in the experiment.

\begin{tabular}{|l|l|l|l|}
\hline Levels & $\begin{array}{l}\text { (A) } \\
\text { Cutting speed } \\
(\mathrm{m} / \mathrm{min})\end{array}$ & $\begin{array}{l}\text { F) } \\
\text { Feed rate } \\
(\mathrm{mm} / \mathrm{rev})\end{array}$ & $\begin{array}{l}\text { (C) } \\
\text { Depth of cut } \\
(\mathrm{mm})\end{array}$ \\
\hline 1 & 27.14 & 0.10 & 0.25 \\
\hline 2 & 33.92 & 0.13 & 0.50 \\
\hline 3 & 43.73 & 0.18 & 0.75 \\
\hline
\end{tabular}

The $\mathrm{S} / \mathrm{N}$ ratio characteristics can be branched into three groups by the three equations given below: Nominal is the best characteristic 
$\frac{S}{N}=10 \log \frac{\bar{y}}{s_{y}^{2}}$

Smaller is the best characteristic

$\frac{S}{N}=-10 \log \frac{1}{n}\left(\Sigma y^{2}\right)$

Larger is the best characteristic

$\frac{S}{N}=-\log \frac{1}{n}\left(\Sigma \frac{1}{(y)^{2}}\right)$

Where $\bar{y}$ is the average value of the observed data,

$s_{y}^{2}$ is the variation of $\mathrm{y}$,

$\mathrm{n}$ is the number of observations,

$\mathrm{y}$ is the observed or recordeddata.

\section{RESULTS AND DISCUSSIONS}

Surface roughness forms a critical parameter in manufacturingof finished components along with dimensional tolerance. Thus this experiment is conducted using Taguchi's method to know the combinations and factors which aid to procure minimum surface roughness values in the machining process. "Smaller the better" characteristic (equation no. 2) was chosen in tinvestigation so as to get the optimum combinations for minimum surface roughness in all three different machining conditions.

\subsection{Dry Machining}

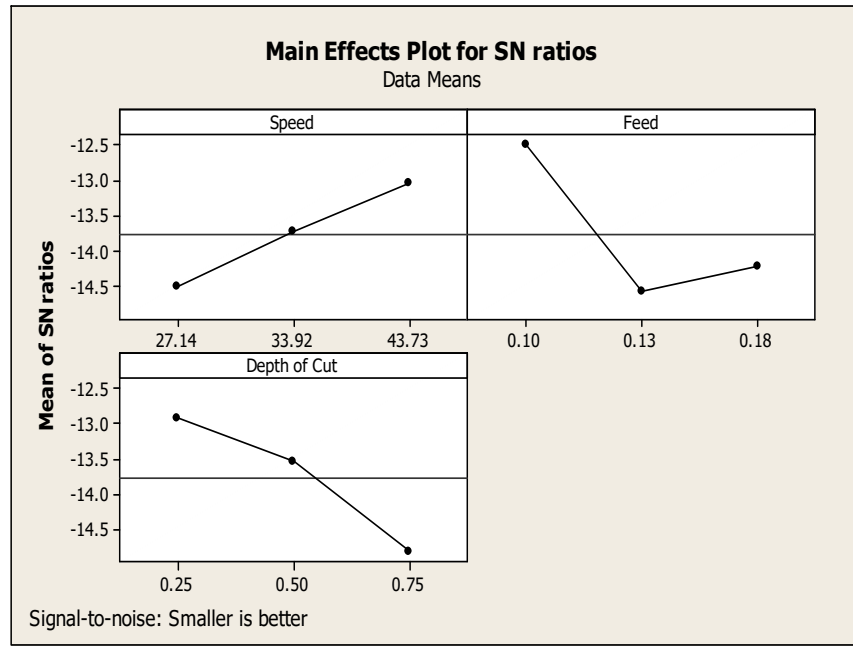

Figure 3: Mean $\mathrm{S} / \mathrm{N}$ ratio graph for surface roughness under dry machining.

Table No.2: Response table for signal to noise ratios of surface roughness obtained during dry machining (Smaller the better).

\begin{tabular}{|c|c|c|c|}
\hline Level & Cutting Speed & Feed rate & Depth of cut \\
\hline 1 & -14.52 & -12.5 & -12.93 \\
\hline 2 & -13.74 & -14.59 & -13.55 \\
\hline 3 & -13.05 & -14.22 & -14.82 \\
\hline Delta & 1.47 & 2.09 & 1.89 \\
\hline Rank & 3 & 1 & 2 \\
\hline
\end{tabular}

Fig. 3 shows the signal to noise ratio graphs obtained for surface roughness under dry machining of AISI 1040 steel and table no. 2 shows the response table for the same. Dry machining was conducted on AISI 1040 steel as it is widely used in industries under ambient condition.It is evident from the ranking and the graph that feed rate is a significant control factor for surface roughness in dry machining proceeded by depth of cut and cutting speed. The signal to noise ratiovalues forsurface roughness increased as the values for feed rate augmented and vice-versa but there was no proportionate increase observed. Feed rate forms a significant factor as lesser the amount of tool feed to the work, it would provide more time for tool to turn the work conveniently thus reducing the surface roughness values. Feed rate of $0.10 \mathrm{~mm} / \mathrm{rev}$, depth of cut of $0.25 \mathrm{~mm}$ and cutting speed of $43.73 \mathrm{~m} / \mathrm{min}$ are the optimum combination of control factor that must be adapted to procure minimum surface roughness values under dry machining of AISI 1040 steel.

\subsection{Conventional Cutting Fluidmachining}

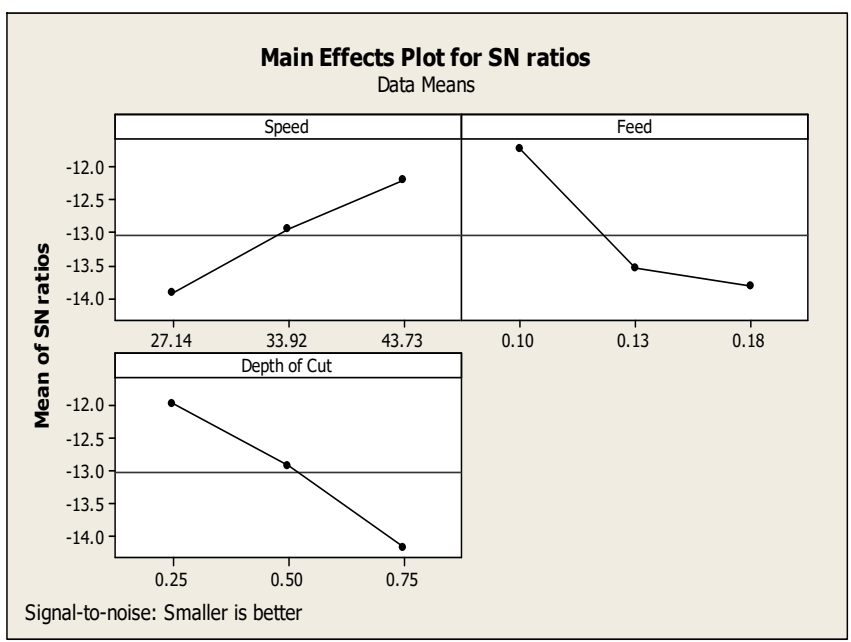

Figure 4: Mean $\mathrm{S} / \mathrm{N}$ ratio graph for surface roughness under wet machining.

Table No. 3: Response table for signal to noise ratios of surface roughness obtained during wet machining (Smaller the better).

\begin{tabular}{|c|c|c|c|}
\hline Level & Cutting Speed & Feed rate & Depth of cut \\
\hline 1 & -13.93 & -11.72 & -11.98 \\
\hline 2 & -12.96 & -13.55 & -12.93 \\
\hline 3 & -12.2 & -13.82 & -14.18 \\
\hline Delta & 1.73 & 2.1 & 2.2 \\
\hline Rank & 3 & 2 & 1 \\
\hline
\end{tabular}

The machining of the work when the cutting fluid (soluble oil) is sent under pressure at the cutting zone uninterruptedlyis referred to as wet machining. Fig. 4 shows the signal to noise ratio graphs obtained for surface roughness under wet machining of AISI 1040 steel and table no. 3 shows the response table for the same. The graphs and the response table indicates that the depth of cut is the furthermostvital control factor for surface roughness under wet machining proceeded by feed rate and cutting speed. 
The values of $\mathrm{S} / \mathrm{N}$ ratio for surface roughness increased with the increase depth of cut and feed rate. It was observed that for minimum depth of cut the $\mathrm{S} / \mathrm{N}$ ratio values were low as there was small amount of material removed and the cutting fluid had the potential to control the cutting zone temperature of this depth of cut value. Thus the surface roughness value was low. $0.10 \mathrm{~mm} / \mathrm{rev}-0.25 \mathrm{~mm}-43.73 \mathrm{~m} / \mathrm{min}$ are the optimum combination of control factor that procured minimum surface roughness values under wet machining of AISI 1040 steel.

\subsection{Cryogenic Machining}

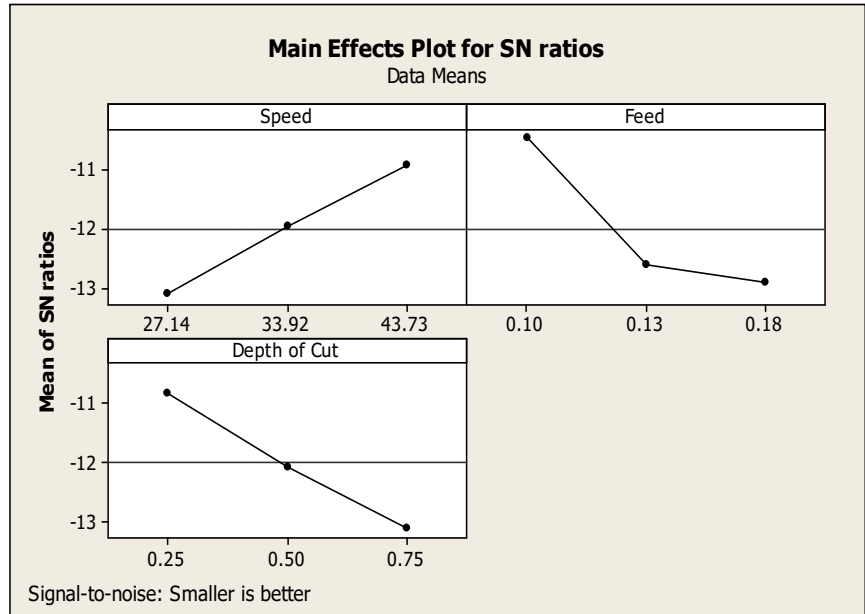

Figure 5: Mean S/N ratio graph for surface roughness under cryogenic machining.

Table No. 4: Response table for signal to noise ratios of surface roughness obtained during cryogenic machining (Smaller the better).

\begin{tabular}{|c|c|c|c|}
\hline Level & Cutting Speed & Feed rate & Depth of cut \\
\hline 1 & -13.11 & -10.49 & -10.84 \\
\hline 2 & -11.97 & -12.63 & -12.07 \\
\hline 3 & -10.93 & -12.91 & -13.11 \\
\hline Delta & 2.18 & 2.42 & 2.27 \\
\hline Rank & 3 & 1 & 2 \\
\hline
\end{tabular}

Fig. 5 illustrates the signal to noise ratio graphs acquired for surface roughness under cryogenic machining of AISI 1040 steel and table no. 4 shows the response table for the same. Feed rate was found to be the most substantial control factor for surface roughness proceeded by depth of cut and cutting speed. Liquid nitrogen (LN2) was successful in providing cryogenic cooling at low feed rates thus thereby reducing the $\mathrm{S} / \mathrm{N}$ ratio values. $0.10 \mathrm{~mm} / \mathrm{rev}-0.25 \mathrm{~mm}-43.73 \mathrm{~m} / \mathrm{min}$ are the optimum combinationof control factor that procured minimum surface roughness values under cryogenic machining of AISI 1040 steel. In analogous to all the S/N ratio values obtained, the values of $\mathrm{S} / \mathrm{N}$ ratio for cryogenic machining with minimum surface roughness combinationwere found to be the least. Thus it can be proved that cryogenic machining is out rightly favorable for acquiring minimum surface roughness.

\section{CONCLUSIONS}

- In dry machining, feed rate acquired the position of most significant control factor proceeded by depth of cut and cutting speed.

- In wet machining, depth of cut procured thefirst rank of significant control factor proceeded by feed rate and cutting speed which were second and third respectively.

- In cryogenic machining, feed rate acquired the first rank of significance of control factor lined up by depth of cut and cutting speed which secured second and third rank.

- The optimumcombinations of control factor (feed ratedepth of cut-cutting speed) for acquiring minimum surface roughness in each of the machining condition are $0.10 \mathrm{~mm} / \mathrm{rev}-0.25 \mathrm{~mm}-43.73 \mathrm{~m} / \mathrm{min}$. Even though the same optimal combinations have been procured for each of the machining condition, there is an improvement in $\mathrm{S} / \mathrm{N}$ ratio values by $53.57 \%$ in surface roughness of cryogenic machining compared to dry machining and $33.92 \%$ improvementin surface roughness of cryogenic machining compared to wet machining. Thus it can be concluded that cryogenic machining provided minimum surface roughness.

- The $\mathrm{S} / \mathrm{N}$ ratio values obtained for minimum surface roughness combination (optimum) in cryogenic machining were found to be the least. Hence it can be concluded that cryogenic machining provides minimum surface roughness in turning of AISI 1040 steel. It can also be concluded that the signals were more effective and efficient in cryogenic machining compared to other forms of machining.

\section{REFERENCES}

[1]. Philip J. Ross, "Taguchi Techniques for Quality Engineering", McGraw-Hill Book Company, International Edition, 1989, ISBN 0-07-053866-2.

[2]. Aman Aggarwal, Hari Singh, Pradeep Kumar and Manmohan Singh, "Optimizing power consumption for CNC turned parts using response surface methodology and Taguchi's technique - A comparative analysis", Journal of Materials Processing Technology 200, 2008, pp. 373-384.

[3]. Anil Gupta, Hari Singh and Aman Aggarwal, "Taguchi-fuzzy multi output optimization (MOO) in high speed CNC turning of AISI P-20 tool steel", Expert Systems with Applications 38, 2011, pp. 68226828.

[4]. Ilhan Asilturk and Harun Akkus, "Determining the effect of cutting parameters on surface roughness in hard turning using the Taguchi method", Measurement 44, 2011, pp. 1697-1704.

[5]. Ilhan Asilturk and Suleyman Neseli, "Multi response optimisation of CNC turning parameters via Taguchi method-based response surface analysis", Measurement 45, 2012, pp. 785-794.

[6]. Turgay Kivak, Gurcan Samtas and Adem Cicek, "Taguchi method based optimisation of drilling parameters in drilling of AISI 316 steel with PVD 
monolayer and multilayer coated HSS drills", Measurement 45, 2012, pp. 1547-1557.

[7]. Mustafa Gunay, Emre Yucel, "Application of Taguchi method for determining optimum surface roughness in turning of high-alloy white cast iron", Measurement 46, 2013, pp. 913-919.

[8]. Ashok Kumar Sahoo and Swastik Pradhan, "Modeling and optimization of $\mathrm{Al} / \mathrm{SiCp} \mathrm{MMC}$ machining using Taguchi approach", Measurement 46, 2013, pp. 30643072.

[9]. K. Venkata Rao, B.S.N. Murthy and N. Mohan Rao, "Cutting tool condition monitoring by analyzing surface roughness, work piece vibration and volume of metal removed for AISI 1040 steel in boring", Measurement 46, 2013, pp. 4075-4084.

[10]. D. Philip Selvaraj, P. Chandramohan and M. Mohanraj, "Optimization of surface roughness, cutting force and tool wear of nitrogen alloyed duplex stainless steel in a dry turning process using Taguchi method", Measurement 49, 2014, pp. 205-215.

[11]. C.C. Tsao and H. Hocheng, "Evaluation of thrust force and surface roughness in drilling composite material using Taguchi analysis and neural network", Journal of Materials Processing Technology 203, 2008, pp. 342348.

[12]. P. Vijian and V.P. Arunachalam, "Optimization of squeeze cast parameters of LM6 aluminium alloy for surface roughness using Taguchi method", Journal of Materials Processing Technology180, 2006, pp. 161166.

[13]. L B Abhang and M Hameedullah, "Optimization of Machining Parameters in Steel Turning Operation by Taguchi Method", Procedia Engineering 38, 2012, pp. $40-48$.

[14]. V.N. Gaitonde, S.R. Karnik and J. Paulo Davim, "Selection of optimal MQL and cutting conditions for enhancing machinability in turning of brass", Journal of Materials Processing Technology 204, 2008, pp. $459-464$.

[15]. John E. Bringas, Editor, Handbook of Comparative World Steel Standards, ASTM DS67B, Third Edition, 2004, pp. 28.

[16]. Rajesh Nayak, B. Raviraj Shetty and C. Sawan Shetty, "Investigation of Cutting Force in Elastomer Machining Using Taguchi's Design of Experiments", International Journal of Advanced Technology \& Engineering Research (IJATER), Volume 4, Issue 4, July 2014, pp. 50-55, ISSN No: 2250-3536.

[17]. Raviraj Shetty, Raghuvir B. Pai, Shrikanth S.Rao and Rajesh Nayak, "Taguchi's Technique in Machining of Metal Matrix Composites", Journal of the Brazil Society of Mech. Sci. \& Eng., January-March 2009, Vol. XXXI, pp. 12-20.

[18]. Akshaya T. Poojary and Rajesh Nayak, "Investigation of Surface Roughness in Machining of AISI 1040 Steel", International Journal of Mechanical Engineering and Technology (IJMET), Volume 5, Issue 9, September (2014), pp. 36-43, ISSN 0976 6340 (Print), ISSN 0976 - 6359 (Online).

[19]. Akshaya T. Poojary and Rajesh Nayak, "Investigation on Machinability of AISI 1040 Steel", International
Journal of Advances in Mechanical and Civil Engineering, Volume-1, Issue-1, Dec.-2014, pp. 33-39, ISSN: 2394-2827.

[20]. Akshaya T. Poojary, Rajesh Nayak, Stanton Shaun D'Silva, "Effect of Process Factors on Cutting Force in DIP Cryogenic Machining of AISI 1040 Steel Using TAGUCHI'S Approach", International Journal of Advanced Research in Science, Engineering and Technology(IJARSET), ISSN: 2350-0328, Vol. 2, Issue 7, July 2015, pp. 800-809. 